JST 8 (2)(2019)
JURNAL SENI TARI
Terakreditasi SINTA 5
http://journal.unnes.ac.id/sju/index.php/jst

\title{
Nilai Estetika Tari Gambang Semarang pada Komunitas Gambang Semarang Art Company
}

\author{
Vina Dwi Tristiani ${ }^{1}$,Restu Lanjari ${ }^{2}$ \\ Jurusan Pendidikan Sendratasik, Fakultas Bahasa dan Seni, Universitas Negeri Semarang
}

\section{Info Artikel}

Sejarah Artikel

Diterima :

30 Oktober 2019

Disetujui :

10 November 2019

Dipublikasikan :

27 November 2019

Keywords:

Aesthetics; Content of Appearance; Gambang Semarang

\begin{abstract}
Abstrak
Tari Gambang Semarang merupakan salah satu bagian dari pertunjukan Kesenian Gambang Semarang yang dibawakan oleh Gambang Semarang Art Company sebagai hasil akulturasi budaya Cina-Jawa di Kota Semarang. Penelitian ini bertujuan untuk mendeskripsikan dan menginterpretasikan nilai keindahan Tari Gambang Semarang yang meliputi aspek bentuk, isi dan penampilan. Metode penelitian menggunakan metode deskriptif kualitatif dengan pendekatan estetis koreografis dan struktural. Sumber data yang diperoleh berupa person (orang), place (tempat), proccess (kegiatan), dan paper (dokumentasi). Hasil penelitian menunjukkan Tari Gambang Semarang tidak memiliki pola pertunjukan khusus, elemen pertunjukan meliputi tema, gerak, rias dan busana, iringan, tata teknik pentas serta pelaku memiliki makna mengenai penggambaran emosi, sikap manusia dalam kehidupan yang dikemas dengan suasana gembira. Keunikan ragam gerak lingar menjadi ciri khas dan perbedaan dengan tari khas Semarang lainnya, selain itu ragam gerak dasar lain yang digunakan yaitu ngeyek, ngondhek, dan genjot. Saran bagi pelaku kesenian Gambang Semarang dapat terus melestarikan Tari Gambang Semarang dengan tetap menjaga nilai-nilai luhur yang terkandung pada setiap aspeknya.

Abstract

The Gambang Semarang dance is one part of the Gambang Semarang Ant Company show as one of the results of the acculturation of Chinese-Javanese culture in Semarang. This study aims to describe and interpret the beautyfull value of the Gambang Semarang Dance which includes aspects of form content and appearance. The research method used qualitative methods with aesthetic choreographic and structural approaches. Sources of data obtained in the form of person (person), place (place), proccess (activity), and paper (documentation). The results showed the Semarang Gambang Dance did not have a special pattern of performance, the elements of the show include themes, movements, make-up and costume, accompaniment performance techniques and performers have meaning regarding depictions of emotions human attitudes in life that are packed with a happy atmosphere. The uniqueness of the linggar range of motion becomes a characteristic and difference with other typical Semarang dances besides that the other basic range of motion used is ngeyek, ngondhek, and geniot Suggestions for Semarang Gambang art performers can continue to preserve the Semarang Gambang Dance while maintaining the noble values contained in each aspect.
\end{abstract}

(C) 2019 Universitas Negeri Semarang

\begin{tabular}{ll}
\hline Alamat korespondensi: & ISSN 2503-2585 \\
Gedung B2 Lantai 1, Fakultas Bahasa dan Seni, UNNES & \\
Kampus Sekaran, Gunungpati, Semarang, 50229 & \\
Email : 1 vinatristiani@gmail.com & \\
2. restulaniari1961@mail.unnes.ac.id &
\end{tabular}




\section{PENDAHULUAN}

Keindahan atau estetika karya tari tidak lepas dari berbagai macam elemen yang menyusunnya. Aspek wujud atau bentuk, bobot atau isi serta penampilan merupakan faktor penilaian dari sebuah keindahan tari. Djelantik (2004) dalam bukunya menyebutkan bahwa keindahan adalah segala sesuatu yang dapat menimbulkan kesenangan, rasa puas, aman, nyaman hingga terpesona dan bahkan mampu menimbulkan keinganan untuk mengalami kembali perasaan tersebut walaupun sudah dinikmati berulangkali dari keseluruhan elemen yang mendukung.Sehubungan dengan estetika atau keindahan dapat memberikan sebuah pedoman terhadap pola perilaku manusia yang berkesinambungan dengan keindahan itu sendiri. Diantaranya, (1) estetika menjadi pedoman bagi seniman untuk mengekspresikan kreasi artistiknya; (2) estetika memberikan pedoman bagi penikmat untuk menyerap karya seni tersebut berdasarkan pengalamannya melakukan pengalaman estetik tertentu (Bahari 2008: 47).

Semarang merupakan sebagai kota multikultural memiliki sebuah pertunjukan khas dan lahir dari inisiatif serta dukungan masyarakat Semarang yang membutuhkan sebuah hiburan. Kesenian Gambang Semarang merupakan salah satu sajian khas, juga sebagai identitas Kota Semarang dan tercipta dari akulturasi budaya Cina-Jawa. Kesenian ini diadaptasi dari kesenian Gambang Kromong yang berasal dari Jakarta namun tetap memiliki akar historis yang tidak bisa lepas dari Semarang. Kesenian Gambang Semarang lahir dan berkembang pada tahun 1940-an berupa sajian seni musik, seni vokal, seni lawak dan seni tari. Penyanyi Kesenian Gambang Semarang, Nyonya Sam memiliki goyangan erotis yang mampu membuat para penikmatnya terbuai hingga lambat laun diturunkanlah penyanyi generasi selanjutnya yaitu Heny. Heny mengadaptasi gerakan Nyonya Sam, dan memberikan istilah yang sampai saat ini digunakan dan dipatenkan oleh seniman Semarang yaitu ragam gerak ngeyek, ngondhek, dan genjot.

Seni tari yang tampil pada Kesenian Gambang Semarang adalah Tari
Gambang Semarang. Perbedaan yang terlihat dan menjadikan keunikan dari Tari Semarangan lainnya adalah penggunaan rias busana berupa jarik yang bermotif burung merak, bentuk tata rias rambut, sikap tangan linggar yang digunakan pada Tari Gambang Semarang serta penggabungan dua iringan tari Gado-Gado Semarang dan iringan Tari Denok. Berdasarkan keunikan tersebut, peneliti tertarik untuk meneliti nilai keindahan Tari Gambang Semarang dan bertujuan untuk mengetahui, mendeskripsikan serta menginterpretasikan baik dari segi wujud, bobot dan penampilan serta elemen pertunjukan dengan menggunakan teori Maryono (2015: 52-71) yang meliputi tema, gerak, rias dan busana, iringan, tata teknik pentas, pelaku. Manfaat dari penelitian ini adalah untuk memberikan khasanah serta wawasan bagi pembaca dan sebagai referensi pada penelitian selanjutnya. Penelitian Nilai Estetika Tari Gambang Semarang pada Grup Komunitas Gambang Semarang Art Company ini menggunakan metode deskriptif kualitatif dan pendekatatan estetis koreografis seta struktural.

Objek kajian penelitian dilakukan pada salah satu komunitas yang bergerak di bidang pelestarian Kesenian Gambang Semarang yaitu Komunitas Gambang Semarang Art Company. Pemilihan Komunitas Gambang Semarang Art Company ini dilatarbelakangi dengan adanya perbedaan sajian tarian yang mencolok dibandingkan dengan dua komunitas lainnya, Nangnok Gambang Semarang dan Kesenian Gambang Semarang milik Universitas Diponegoro. Sajian Tari Gambang Semarang ciptaan Dewi Indah, berbeda dengan tari yang dibawakan pada dua komunitas tersebut yang membawakan Tari Gado-Gado Semarang dan Tari Denok. Nilai Estetika Tari Gambang Semarang pada Grup Komunitas Gambang Semarang Art Company dibedah dengan menggunakan teori Djelantik dan Maryono. Elemen pertunjukan Tari Gambang Semarang, meliputi tema, gerak, rias dan busana, iringan, tata teknik pentas dan pelaku.

Penelitian yang relevan dan terbaru milik Wida tahun 2018 dengan kajian Manajemen pertunjukan Kesenian 
Gambang Semarang studi kasus: Komunitas Gambang Semarang Art Company membahas mengenai profil, persiapan serta bentuk manajemen yang dilakukan oleh komunitas GSAC pada setiap pentasnya yang digunakan peneliti sebagai referensi serta bentuk kontribusi informasi bagi penelitian Nilai Estetika Tari Gambang Semarang pada Komunitas Gambang Semarang Art Company.

\section{METODE PENELITIAN}

\section{Nilai Estetika Tari Gambang} Semarang pada Grup Gambang Semarang Art Company menggunakan metode penelitian deskriptif kualitatif atau biasa disebut dengan metode artistik, naturalistik, karena penelitiannya dilakukan pada kondisi alamiah dimana peneliti memiliki tujuan untuk mengetahui suatu nilai, fenomena pada suatu objek dalam kasus Tari Gambang Semarang yang memiliki konteks atau setting alamiah. Data yang disajikan berupa deskripsi, kata-kata tertulis yang didapatkan oleh peneliti dengan menggunakan pengamatan berperanserta, terjun langsung dan berbaur dengan pelaku Gambang Semarang. Pendekatan yang digunakan pada penelitian yaitu pendekatan struktural dan estetis koreografis. Pendekatan struktural bertujuan guna menguraikan dan menganalisis setiap bagian, elemen, aspek, yang tersusun pada Tari Gambang Semarang, sedangkan pendekatan estetis koreografis bermaksud untuk menguraikan serta menginterpretasikan nilai keindahan Tari Gambang Semarang.

Beberapa sumber data yang digunakan oleh peneliti menggunakan teori milik Rohendi $4 p$ diantaranya; person (narasumber) meliputi pencipta Tari Gambang Semarang, pemusik Gambang Semarang, penari Gambang Semarang serta Direktur GSAC. Place (tempat), atau lokasi penelitian yang berada pada beberapa titik yaitu Fakultas Ilmu Budaya Universitas Diponegoro, Kesekretariatan GSAC J1. Subali Raya, Krapyak Semarang, kediaman pencipta tari di Graha Avisena Residence, Pedurungan, Semarang serta PKM Universitas Diponegoro. Process (kegiatan), kegiatan yang diteliti berupa proses latihan rutin GSAC serta pementasan pertunjukan Tari Gambang Semarang. Paper (dokumentasi), bentuk dokumentasi yang diambil oleh peneliti berupa foto dan video latihan pementasan Tari Gambang Semarang. Jenis data yang digunakan dalam penelitian yaitu data primer dan data sekunder. Data primer didapatkan dari hasil wawancara dengan pencipta Tari Gambang Semarang, Direktur GSAC dan data sekunder dari penari dan pemusik Gambang Semarang. Selanjutnya ada tiga teknik pengumpulan data yang digunakan dalam penelitian yaitu teknik observasi, teknik wawancara dan teknik dokumentasi.

Observasi dilakukan tiga kali. Pada observasi pertama, peneliti terjun langsung tanggal 15 April 2019 bertempat di Gedung Sejarah Fakultas Ilmu Budaya Universitas Diponegoro saat melakukan latihan pentas Tari Gambang Semarang. Observasi berikutnya dilakukan dua kali, pada tanggal 20 April 2019 dan 25 Juni 2019 pada acara Gelar Sangkatama UKM UPGRIS dan pentas yang bertempat di Joglo Fakultas Ilmu Budaya Universitas Diponegoro dengan hasil observasi berupa pementasan Tari Gambang Semarang.

Teknik wawancara dilakukan lima kali dengan empat lokasi dan narasumber yang berbeda. Pada wawancara pertama dan ke empat, peneliti melakukan dengan pencipta Tari Gambang Semarang Dewi Indah (62) yang berada di kediamannya Perumahan Graha Avisena Residence, Jl. Fatmawati 1 No. 1 Kelurahan Pedrungan, Semarang tanggal 10 April 2019 dan 18 Juni 2019 mengenai bagaimana proses penciptaan Tari Gambang Semarang serta nilai-nilai yang terkandung di dalamnya. Wawancara berikutnya dengan Direktur Gambang Semarang Art Company, Tri Subekso (40) bertempat di Kesekretariatan GSAC J1. Subali Raya Kav. 334 RT 02 RW 04 Krapyak, Semarang dengan data penelitian mengenai sejarah dan profil komunitas Gambang Semarang Art Company. Wawancara ketiga dengan salah satu pemusik Gambang Semarang Sigit Purnomo (23) bertempat di Fakultas 
Ilmu Budaya Universitas Diponegoro dengan hasil data berupa alat musik Gambang Semarang, notasi dan iringan Tari Gambang Semarang serta makna yang terkandung didalamnya. Wawancara kelima dengan narasumber penari Gambang Semarang, Khoirul Bariyah (21) yang dilakukan di Fakultas Ilmu Budaya Universitas Diponegoro dengan hasil data meliputi teknik tari yang digunakan, kriteria penari, kepenarian, serta alasan mengapa tertarik mempelajari Tari Gambang Semarang. Teknik dokumentasi yang dilakukan oleh peneliti yaitu pengambilan dokumentasi dalam bentuk foto dan video baik saat melakukan wawancara dengan narasumber, proses latihan rutin serta pertunjukan Tari Gambang Semarang.

Analisis data yang dilakukan peneliti menggunakan teori Adshead yaitu, dengan mengamati, memahami, melakukan interpretasi serta melakukan evaluasi terhadap objek kajian Tari Gambang Semarang dan menarik kesimpulan. Uji keabsahan data yang dilakukan menggunakan tiga teknik triangulasi, yaitu triangulasi sumber untuk membuktikan kebenaran antara narasumber untuk menghasilkan data yang kredibel, triangulasi teori yang berguna untuk membandingakan data yang didapatkan di lapangan dengan teori yang digunakan serta triangulasi teknik yaitu berbagai macam teknik pengambilan data berupa observasi, wawancara serta dokumentasi.

\section{HASIL DAN PEMBAHASAN}

Sejarah Komunitas Gambang Semarang Art Company

Gambang Semarang Art Company merupakan salah satu komunitas diantara tiga komunitas yang berkecimpung dalam kesenian Gambang Semarang. Komunitas Gambang Semarang Art Company atau GSAC ini mengembangkan kesenian dan menitikberatkan pada nilai aktual dan kreativitas. Setiap pertunjukan, Gambang Semarang Art Company selalu membawakan Tari Gambang Semarang dan Tari Goyang Semarang sebagai identitasnya. Tari Gambang Semarang merupakan akulturasi berbagai macam budaya Cina, Jawa, Arab dan Eropa yang diciptakan oleh Dewi Indah guna kebutuhan pentas serta sebagai sarana hiburan bagi warga Kota Semarang. Ciri khas ragam gerak berupa ngeyek, ngondhek, nggenjot, dan jalan tepak serta bentuk tangan linggar ini menjadikan perbedaan yang membuat peneliti semakin tertarik untuk mengupas nilai keindahan Tari Gambang Semarang garapan Dewi Indah. Iringan yang digunakan yaitu perpaduan dari lagu Gado-gado Semarang dan Gambang Semarang. Komunitas GSAC berdiri sejak 21 November 2012 dengan tujuan untuk meneruskan, mengenalkan, mengembangkan dan melestarikan kesenian Gambang Semarang yang merupakan bentuk akulturasi nyata adanya percampuran berbagai macam budaya. Visi misi dari GSAC adalah kembali mendekatkan Gambang Semarang sebagai identitas Kota Semarang kepada masyarakat. Misi yang telah dilakukan adalah mementaskan pertunjukan Gambang Semarang di beberapa kampung di Kota Semarang. Pementasan tersebut cukup kuat untuk menarik penonton dari awal persiapan hingga pementasan berakhir. Hal tersebut didukung oleh pernyataan Tri Subekso, wawancara pada tanggal 30 April 2019, sebagai berikut:

"...GSAC mulai didirikan pada tanggal 21 November 2012. Nah, apa yang melatarbelakangi pendirian GSAC ini adalah bahwa ini salah satu merupakan bentuk kegelisahan dari kami, melihat bahwa Kesenian Gambang Semarang mendekati kepunahan. Karena satu-satunya Grup Gambang Semarang yang masih ada, dimana ketuanya Pak Jayadi sudah meninggal dan tidak ada penerusnya. Nah, padahal dari kami ada hasrat yang besar untuk melestarikan dan mengembangkan kesenian ini lagi. Visi misi kami adalah, kami ingin kembali..."

\section{Sejarah Tari Gambang Semarang}

Tari Gambang Semarang karya Dewi Indah termasuk dalam tari kreasi 
kerakyatan yang digarap pada tahun 1999. Proses garap awal Tari Gambang Semarang ini bermula dari penelitian Dhanang Respati Puguh tahun 1999 mengenai penataan kesenian Gambang Semarang yang dimana Dewi Indah terlibat sebagai tim dari penelitian Penataan Kesenian Gambang Semarang. Tari Gambang Semarang ini adalah tarian yang sudah ditata sedemikian rupa dan diangkat dari gerak tubuh Nyonya Sam dan Heny yang dahulunya terkenal erotis hingga menimbulkan kecemasan apabila gerakan tersebut tidak dikontrol. Heny sendiri merupakan generasi penerus dari Nyonya Ong Sam Nio atau dikenal dengan panggilan Nyonya Sam yang dahulunya hanya sebagai penikmat kemudian menjadi penerus. Melalui penelitian tersebut ditatalah sebuah gerak tari yang indah namun tidak meninggalkan gerakan khas dari Heny yaitu ragam gerak ngeyek, ngondhek, genjot kemudian ditambahan ragam gerak tangan linggar oleh Dewi Indah serta tidak menimbulkan kesan keerotisan. Ragam gerak tangan nglinggar yaitu ujung ibu jari dan jari telunjuk disatukan membentuk lingkaran, kemudian ketiga jari yaitu jari tengah, jari manis dan jari kelingking dibuka keluar dengan posisi renggang. Linggar berasal dari kata "lingkaran" dan "tiga". Dewi mengartikan linggar sebagai bentuk pengendalian emosi diri manusia. Makna pengendalian emosi tersebut diambil dari beberapa pentas Gambang Semarang pada zaman dahulu yang apabila tidak ditata, mampu menimbulkan efek negatif bagi penikmatnya. Tari Gambang Semarang memiliki makna berupa pengendalian diri emosi manusia.

\section{Estetika Tari Gambang Semarang Bentuk}

Djelantik (1999: 21) menyebutkan bahwa bentuk adalah sebuah kumpulan titik yang apabila dikumpulkan akan tercipta sebuah pola, begitu pula tari yang tersusun dari berbagai macam gerak. Bentuk tari meliputi pola dan elemen pertunjukan. Pola pertunjukan dalam tari memiliki beberapa istilah, seperti Maju beksan, beksan dan mundur beksan. Adapula yang menggunakan istilah pola awal, pola inti dan pola akhir. Dewi mengungkapkan bahwa tidak ada pembagian pola tertentu diaganggap semua bagian tari adalah satu kesatuan yang utuh.

Elemen pertunjukan menurut Maryono (2015:52-71) meliputi tema, gerak, rias dan busana, iringan, tata teknik pentas dan pelaku. Tema dari Tari Gambang Semarang adalah pergaulan dan kegembiraan. Sesuai dengan ragamragam gerak yang hadir dalam tarian, Tari Gambang Semarang ini cocok digunakan sebagai tari hiburan, Penggambaran kegembiraan dapat dilihat dari ekspresi penari serta lirik pada iringan Tari Gambang Semarang sebagai berikut:

"...sambil menyanyi, jongkok berdiri
kaki melintang
Aduh, sungguh jenaka waktu mereka
tari berdendang
Bersuka ria, gelak tertawa semua
orang karena
Hati tertarik, grak grik si tukang
kendhang
Empat penari membikin hati
menjadi senang
Aduh, itulah dia malam gembira,
gambang semarang...”

Bentuk garap Tari Gambang Semarang dengan tema pergaulan dan kegembiraan ini juga diangkat dari nilai sosial masyarakat Kota Semarang yang senang bercanda, berkumpul dan grapyak. Atmosfer atau susasana kegembiraan tarian dapat tangkap dan dirasakan oleh penonton.

Tari Gambang Semarang memiliki ciri khas ragam gerak berupa ngondhek, ngeyek dan genjot serta tidak lupa pula ragam gerak linggar yang menjadi perbedaan dengan tarian Semarangan lainnya. Ngondhek adalah gerak putaran ke kanan dan ke kiri yang memiliki lintasan menyerupai angka delapan. Ngeyek adalah gerakan pinggul ke kanan dan ke kiri secara patah-patah. Genjot yaitu gerakan tubuh yang memegas ke atas dan ssecara bersamaan menggerakkan pinggul ke kanan dan ke kiri. Kemudian ragam gerak tangan linggar yaitu ujung ibu jari dan jari telunjuk disatukan membentuk lingkaran, 
kemudian ketiga jari yaitu jari tengah, jari manis dan jari kelingking dibuka keluar dengan posisi renggang. Ragam gerak lainnya yaitu menthang asta ngayuh lampah, ukel geol, sikap, lampah menthang nimbang asta, nimbang asta, sangga nampa ngayuh lampah, ngendhap, gertak, lampah ngayuh nimbang asta, ngombak, lampah ngriyak ngawe asta, linggar berputar dan heniing. Menurut penilaian mengenai aspek gerak yang ditinjau dari segi ruang, tenaga dan waktu Tari Gambang Semarang memiliki keindahan dari gerak yang dinamis, namun tidak menghilangkan kesan kenes serta sigrak yang dapat dilihat permainan tempo iringan yang digunakan.

Tata rias yang digunakan pada Tari Gambang Senarang meliputi tata rias wajah, yang meggunakan rias formal dengan menciptakan kesan cantik, anggun, segar dan menawan. Kesan tersebut muncul dari pemilihan warna eyeshadow yang cerah sehingga mampu membuat mata penari terlihat gembira, pemilihan blush on yang merona serta pemilihan warna lipstik merah yang mampu membuat penonton tertarik menikmati Tari Gambang Semarang. Tata rias rambut Tari Gambang Semarang menggunakan sanggul yang berbentuk menyerupai tumpeng segitiga dan sanggul kadhal menek yang dihiasi dengan manikmanik berwarna emas, aksesories berupa ronce melati, sirkam, minthi dan tusuk cina. Dari berbagai pendukung tata rias rambut maka nilai keindahan tata rias rambut Tari Gambang Semarang merupakan gambaran keadaan geografis serta nilai filosofis yang dianut oleh masyarakat Semarang dan saling terkait antar unsurnya. Tata rias busana yang digunakan yaitu berupa kebaya encim, jarik bermotif burung merak dan pohon bambu dengan hiasan manik-manik, slepe dan tothok, sampur serta aksesoris giwang, kalung. Penggunaan jarik bermotif burung merak dan pohon bambu memiliki makna sebagai permohonan do'a dan keagungan

Iringan Tari Gambang Semarang merupakan penggabungan dua iringan Gado-gado Semarang dan Empat penar. Penggabungan dua iringan dilatarbelakangi bahwa kedua lagu tersebut sudah menjadi legenda dan ciri khas dari identitas Kota Semarang. Alat musik yang digunakan yaitu kendhang, boning, gambang kontra bass, gambang melodi, kecrek, demung, saron, peking, gong kempul, dizi, gu zheng, yangqin, erhu dan chong $h u$. Perpaduan alat musik Cina dan Jawa adalah bentuk nyata daanya akultrasi dari kedua budaya yang ada di Kota Semarang. Alat musik gamelan Jawa yang digunakan menggunakan rancakan kijingan dan bunga ceplok sebagai simbol untuk mengingatkan manusia mengenai kehidupan selanjutnya. Nada yang digunakan pada iringan adalah nada diatonis.

Tata teknik pentas yang digunakan meliputi tata panggung, tata suara dan tata cahaya pada Tari Gambang Semarang idealnya menggunakan panggung berbentuk proscenium yang cukup luas dan menampung adanya penari serta pemusik dalam pertunjukan. Penataan cahaya menggunakan lampu general serta tata suara berupa pengeras suara. Mengingat bahwa pertunjukan Kesenian Gambang Semarang adalah pertunjukan kerakyatan, maka cenderung berbaur dengan masyarakat.

Pelaku Tari Gambang Semarang terdiri dari penari dan pemusik. Tari Gambang Semarang, ditarikan oleh empat penari perempuan yang memiliki postur tubuh yang sama, tidak terlalu mencolok baik tinggi maupun berat badan dan berusia 19-22 tahun. Kemampuan penari harus seimbang untuk mencapai titik keharmonisan, baik wiraga, wirama, wirasa dan wirupa. Pemusik Gambang Semarang berusia berkisar 20 hingga 80 tahun. Nilai keindahan penari dan pemusik terlihat saat melakukan pertunjukan Gambang Semarang.

\section{Isi}

Djelantik mengungkapkan bahwa isi atau makna sebuah karya dapat ditangkap langsung oleh pengamatnya melalui beberapa aspek diantaranya, ide, suasana, pesan. Isi yang terkandung dalam Tari Gambang Semarang meliputi ide, suasana dan pesan. Ide penciptaan tari berawal dari penelitian yang dilakukan oleh Dhanang untuk menata kembali kesenian Gambang Semarang dan menciptakan karya tari 
yang mencerminkan budaya serta masyarakat Semarang. Suasana pertunjukan Tari Gambang Semarang adalah suasana kegembiraan, semangat serta energik mengingat bahwa salah satu fungsi dari kesenian Gambang Semarang adalah sebagai hiburan. Pesan yang ditemukan oleh peneliti adalah pengendalian emosi dalam hidup. Walaupun tidak bersumber dari cerita legenda Semarang namun, memiliki pesan yang disampaikan melalui goyang pinggul yang khas sebagai bentuk gambaran gelombang laut yang menghiasi garis pantai Kota Semarang seperti emosi manusia yang naik dan turun, maka harus mampu menimbang, mengontrol setiap keputusan

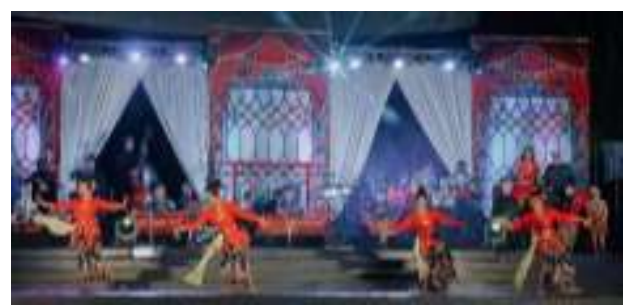

Foto 1. Pementasan Tari Gambang Semarang (Sumber: Tim Dokumentasi GSAC, 28 September 2019)

Penampilan

Aspek penampilan karya seni menurut Djelantik meliputi bakat, keterampilan dan sarana. Bakat pencipta tari Gambang Semarang, Dewi Indah didapatkan dari genetik dan pelatihan kepenarian yang dilakukan jauh sebelum menciptakan Tari Gambang Semarang, sedangkan bakat kepenarian penari didapatkan dari latihan rutin yang dilakukan sebagai persiapan pentas. Aspek keterampilan dari penari dan pemusik diasah melalui latihan rutin dan proses evaluasi setiap latihan dan pementasan berakhir, sedangkan sarana yang digunakan berupa audio, visual maupun keduanya. Media audio berupa alat musik, sedangkan media visual berupa pengolahan wiraga, wirama, wirasa dan wirupa.

\section{SIMPULAN}

Berdasarkan hasil penelitian Nilai Estetika Tari Gambang Semarang pada Komunitas Gambang Semarang Art Company menunjukkan bahwa komunitas ini menampilkan kesenian Gambang Semarang yang terdiri dari lawak, musik dan tari. Tari Gambang Semarang tergolong dalam jenis tari noncerita memiliki ragam gerak dasar ngeyek, ngondhek, genjot dan linggar. Perpaduan unsur Cina dan Jawa mencerminkan keanekaragaman seni budaya yang hadir di Kota Semarang dan direfleksikan melalui setiap elemen pertunjukan. Tari Gambang Semarang karya Dewi Indah tidak memiliki pola pertunjukan khusus, karena hanya merupakan gambaran kehidupan aktivitas masyarakat Semarang yang hidup harmonis, memiliki karakter terbuka, mudah bergaul. Elemen pertunjukan tari bagian gerak menunjukkan bahwa goyang pinggul dan pantat adalah gerak menujukkan bahwa goyang pinggul dan pantat adalah gerak penonjolan yang khas serta mampu menimbulkan kesan kenes, tidak berlebihan dalam bergerak sesuai dengan karakter masyarakat yang biasabiasa saja. Permainan tempo, aksen gerak yang patah-patah kemudian halus yang kerap berubah diciptakan agar tidak terkesan monoton, membosankan.

\section{DAFTAR PUSTAKA}

Bahari, N. (2008). Kritik Seni Wacana, Apresiasi dan Kreasi. Yogyakarta: Pustaka Pelajar

Djelantik. (1999). Estetika Sebuah Pengantar. Bandung: PT. Kiblat Buku Utama

https://doi,org./10.15294/jst.v8j.30632 Maryono. (2015). Analisa Tari. Surakarta: ISI Press

Puguh, R. (2000). Pentaan Kesenian Gambang Semarang sebagai Identitas Budaya Semarang. UNDIP: Dinas Pendidikan Nasional

Wida, S. (2017). Manajemen pertunjukan Kesenian Gambang Semarang studi kasus: Komunitas Gambang Semarang Art Company. Skripsi UNNES 